\title{
Award-winning paper in 2010
}

Papers published in Urban Design and Planning are eligible for awards from the Institution of Civil Engineers. Papers from any of the ICE journals can be nominated for several awards. In addition, each journal has awards dedicated to their specific subject area.

On Monday 24 October 2011, ICE president Peter Hansford presented an award to the following paper published in Urban Design and Planning in 2010. The editorial panel nominated their best papers and an awards committee chaired by Barry Clark allocated the awards.

The Reed and Mallik Medal was awarded to: Power A (2010) Housing and sustainability: demolition or refurbishment? Proceedings of the Institution of Civil Engineers - Urban Design and Planning 163(4): 205-216, http://dx.doi.org/10.1680/udap.2010.163.4.205.

\begin{abstract}
The demolition or refurbishment of older housing has been an active policy area since the late 1880s in the UK, when the government first authorised the statutory demolition of unsanitary slums. The debate on demolition and new building has been intensified since 2003, with government proposals for large-scale clearance and new construction. This paper summarises the evidence and debate on whether demolition would reduce greenhouse gas emissions from buildings. It examines whether a more achievable and socially beneficial route to reducing energy use in the built environment exists, based on the fact that buildings account for half of the UK's carbon emissions. This paper argues that large-scale and accelerated demolition would neither help with meeting energy and climate change targets, nor would it address social needs. Refurbishment offers clear advantages in time, cost, community impact, prevention of building sprawl, reuse of existing infrastructure and protection of existing communities. It can also lead to significantly reduced energy use in buildings in both the short and long term.
\end{abstract}

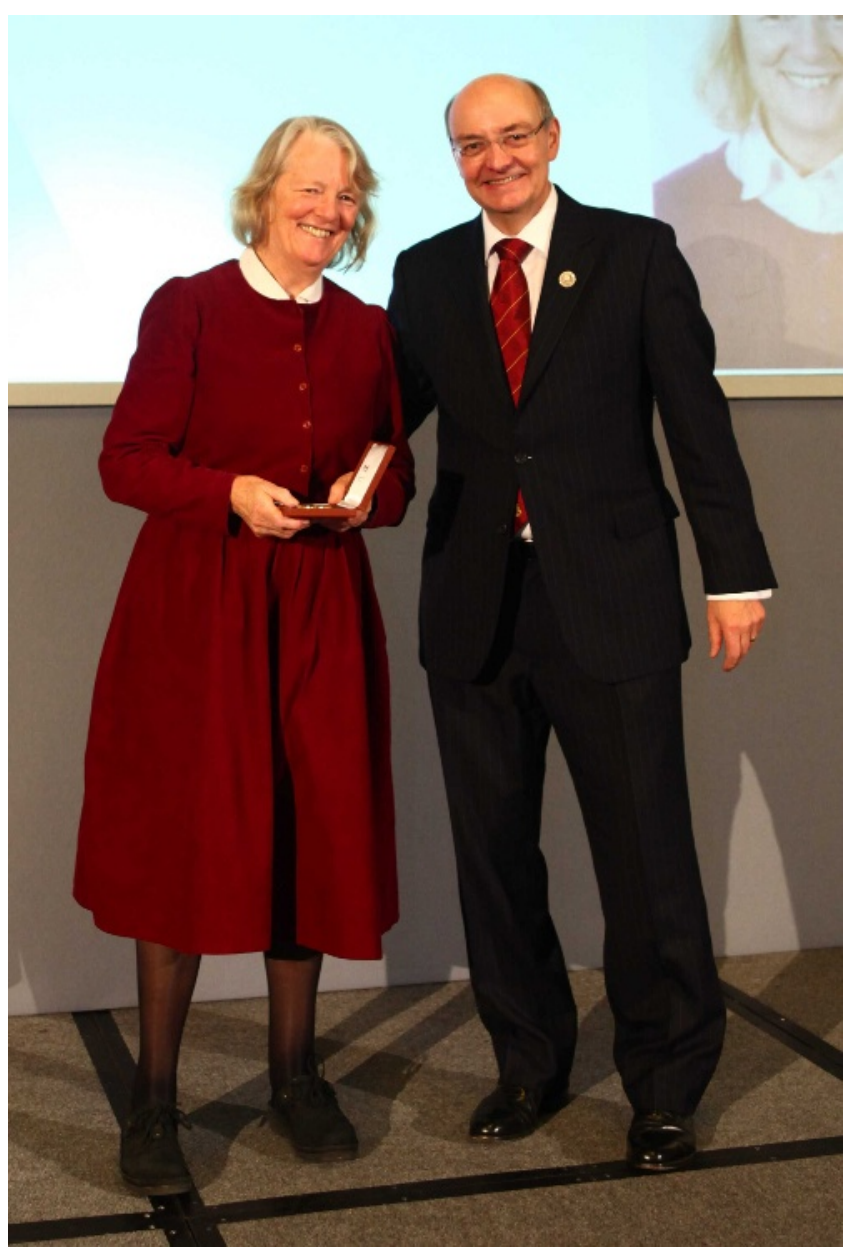

ICE president Peter Hansford presents the Reed and Mallik Medal to winner Anne Power 